\title{
Executing Downsizing: The Experience of Executioners
}

\author{
Franco Gandolfi \\ Regent University, Virginia Beach \\ E-Mail: fgandolfi@regent.edu
}

\begin{abstract}
Downsizing as a managerial strategy has been implemented on a global scale for more than two decades. Most research on the outcomes of downsizing focus on the personal and professional consequences affecting individuals representing two distinct camps: the downsizing survivors and downsizing victims. This Australian case study explored how the executioners, the individuals that were entrusted with the task of carrying out downsizing, experienced their responsibilities. The results derived from one of Australia's largest banks demonstrate that the work of executing downsizing activities is emotionally taxing. It was shown that executioners had a tendency to distance themselves from the tasks emotionally, cognitively, and physically. These strategies were seen as coping mechanisms for self-protection and self-preservation. Previous experience with downsizing enabled executioners to stay on task. Relational proximity and closeness with individual victims further impacted the emotional state of executioners. This study heavily relied upon Clair and Dufresne's (2004) empirical work and generated a preliminary conceptual framework depicting various facets of executioners' reactions to downsizing-related layoffs.
\end{abstract}

Keywords: Downsizing, Executioners, Australia, Bank

\section{INTRODUCTION}

Downsizing is a change management strategy that has been utilized for more than two decades (Williams, 2004). During the 1980s and early 1990s, downsizing was adopted primarily by firms experiencing difficult economic times (Gandolfi, 2006). Since the mid-1990s, downsizing has become a leading strategy of choice for a large number of companies and governmental agencies around the world (Mirabal \& DeYoung, 2005). Downsizing frequently involves the reduction in personnel (Cameron, 1994) and often results in the redesign of work processes to improve a firm's levels of productivity, efficiency, and effectiveness (Kozlowski, Chao, Smith, 
\& Hedlung, 1993). Over the years, this strategy has generated a great deal of interest among scholars and managers alike. Scholars, for example, maintain that the body of knowledge about the practice of downsizing is still underdeveloped considering its prevalence and persistence (Macky, 2004). By far the most extensive work about downsizing concerns its financial and organizational consequences (Gandolfi, 2007).

To date, little research has focused on those individuals who plan and implement downsizing endeavors and how they experience their responsibilities. Literature refers to them as executors (Downs, 1995), downsizers (Burke, 1998), downsizing agents (Clair \& Dufresne, 2004), and executioners (Gandolfi, 2006). Downsizing executioners are individuals entrusted with responsibilities in regard to the planning, execution, and evaluation of downsizing-related activities. This definition is broad encompassing individuals with formal downsizing responsibilities. It also recognizes that different types of people with various professional roles and at different organizational levels conduct downsizing tasks (Clair \& Dufresne, 2004).

\section{DOWNSIZING EXECUTIONERS}

Understanding the executioners is invaluable since their experiences are distinct (Clair \& Dufresne, 2004). Executioners are downsizing survivors (Noer, 1993). At the same time, their experiences differ from those of other survivors due to their dual role as agents of change and receivers (Dewitt, Trevino, Mollica, \& Stuck, 2003). Executioners have a significant impact on the overall downsizing outcome (Gandolfi, 2006) by means of their methods, techniques, and tools (Wright \& Barling, 1998), as well as their influences over employees' reactions (Dewitt et al., 2003). According to Brockner (1992), executioners have the capacity to influence employees' perceptions of equity and justice by means of the selected implementation methods (Wiesenfeld, Brockner, \& Thibault, 2000).

How do executioners respond to their responsibilities? Scholars have theorized about executioners and their reactions to their responsibilities, including Wright and Barling (1998), Dewitt et al. (2003), Clair and Dufresne (2004), and Gandolfi (2006). Their findings reveal that conducting downsizing places considerable professional demands on executioners and engenders long-term emotional effects (Wright \& Barling, 1998). Gandolfi (2006) claims that executioners suffer from similar psychological and emotional effects as downsizing survivors and victims. There is some evidence suggesting that in a number of cases executioners ultimately downsize their own position within their respective firm (Gandolfi \& Neck, 2003). At the same time, executioners need to find effective ways to cope with the pressures of their 
responsibilities (Clair \& Dufresne, 2004). Folger and Skarlicki (1998) examined managers' reactions to the downsizing of employees and ascertained that managers' attributions about the need for downsizing affected managerial distancing behaviors in carrying the downsizing activity in the form of truncated dismissal meetings.

Such distancing behaviors in a downsizing can be seen as actions that decrease an individual's attachment to or involvement in his or her role (Clair \& Dufresne, 2004). Thus, executioners that engage in such behaviors are less likely to be in a position to respond to employees' needs during downsizing. It must be understood that executing downsizing activities, staying connected with downsized individuals, and being present for affected employees during downsizing constitute challenging situations for executioners. Empirical studies of 'death tellers' (i.e., those that are responsible for telling others about the death of a loved one) demonstrate that highly difficult workplace situations laden with negative emotions have a significant impact on how individuals approach and engage with the tasks at hand (Clark \& LaBeff, 1982). Death-tellers are primarily messengers, whereas executioners are implementers of change and, at the extreme of responsibility, individuals whose poor decisions led to the need to resort to downsizing. This added level of responsibility influences when, how, and to what extent executioners connect with their downsizing work.

This study examines how executioners experience downsizing. Of prime importance is the question of how individuals react to their own responsibilities. The study also sheds light on how executioners stay close to and distanced from the downsizing experience. Conceptually, the study is based upon Clair and Dufresne's (2004) empirical work and seeks to apply and confirm their findings in a different industry and geographical setting.

\section{METHODOLOGY}

Macky (2004) suggests that research on downsizing should pursue a theorybuilding approach. This is consistent with recommendations by other prominent scholars, such as Brockner (1992), Cameron (1994), Littler (1998), Morris, Cascio, and Young (1999), and Dolan, Belout, and Balkin (2000). The lack of research being conducted on the executioners required a distinctive approach to research which validated an inductive approach. According to Miles and Huberman (1994), inductive methods have the capacity to build insights grounded in the experience of study participants within a particular context and profoundly assist the research into an understudied area (Yin, 2003). The focus of the processes of data collection, analysis, and interpretation was to engage in a realist-oriented, qualitative approach that 
followed Miles and Huberman's (1994) guidelines. A conscious effort was made to capture real experiences and reactions of executioners (Clair \& Dufresne, 2004).

This study employed the case study methodology. Yin (1989) sees case study research as a form of "empirical inquiry" (p 23) which focuses upon a phenomenon within its real-life context by obtaining data from a multitude of sources in order to analyze the phenomenon in-depth. Thus, the case study method has the capacity to build theory (Yin, 2003). The selection of cases in qualitative case study research is purposeful (Eisenhardt, 1989) and involves the use of replication logic (Carson, Gilmore, Gronhaug, \& Perry, 2001). The selection of individual cases depends largely upon the conceptual framework developed in the literature review and prior theory (Perry, 1998). The ultimate principle of the selection procedure is selecting "information rich cases" (Patton, 1990: 181).

The Australian banking sector has been adversely affected by the deregulation of the finance industry (Gandolfi, 2006). Repercussions have been retrenchments, branch closures, and considerable levels of layoffs (Finance Sector Union, 2005). The size of the workforce in the Australian finance industry has been steadily declining since the early 1990s (Finance Sector Union, 2005). For instance, between 1991 and 1996 the finance industry declined by 8.8 percent (Australian Bureau of Statistics, 1998), and further downsizings have been predicted (Finance Sector Union, 2005).

This study has adopted one of Australia's largest banks as measured by the total number of employees. The case was selected primarily for its accessibility and senior management's willingness to co-operate. The decision to examine a large firm was based upon Keller's (1998) observation that large firms have been the prime targets of downsizing. The Australian Finance Sector Workforce Report reveals that downsizing in banks has been particularly severe since the mid-1990s (Finance Sector Union, 2005). Still, there is a sense that the downsizing of banks is not a phenomenon of the past but an ever-popular management tool (Gandolfi, 2006).

Face-to-face interviews with executioners of the study case were conducted between September 2005 and August 2006. A senior executive of one of Australia's largest banks provided permission to collect data within the bank and presented a list of individuals who were responsible for the planning and execution of downsizing. This study included 20 executioners with various job titles and organizational levels. The key informants included the Chief Executive Officer, Chief Operations Officer, Chief Knowledge Officer, Senior HR Executive, Director of Human Resources, Senior Human Resources Manager, Senior Learning \& Development Manager, Manager Training \& Development, Manager Organization Development, and Human 
Resources Consultants. Participants represented various functional areas, including human resources (HR), operations, finance, and public relations. The inclusion of participants from different hierarchical levels and various functional areas was critical to the success of the study and satisfied the requirement of conducting interviews at different levels (Perry, 1998) within the case-study firm (Carson et al., 2001).

The qualifying criterion for participating executioners was the status of being a survivor (Noer, 1993) in that participants were required to have served the bank before, during, and after the downsizing. Organizational tenure averaged 4.8 years with a range of 1.2 - 15 years. Participants were seen as "informants" (Bogdan \& Biklen, 1998: 32) rather than mere "respondents" (Yin, 1994: 84). There was an expectation that participants would provide information that would in turn have the capacity to build theory. All managers were interviewed only once over the 11-month period with each interview lasting between 45 and 60 minutes. At the outset of the interviews, each participant was assured of total confidentiality. The interviews were focused (Adams \& Schvaneveldt, 1991) and took place in the interviewees' own offices. This allowed the interviewer to probe far beyond the answers to the prepared questions (Berg, 1989). With the consent of the participating firm and individual managers, each interview was taped, and meticulously transcribed and documented. The interview transcripts constituted the main raw material and provided "highly detailed and publicly accessible representations of social interaction" (Silverman, 1997: 203). Although, the study was confined to a single firm, 20 executioners were interviewed. This is consistent with the case study literature suggesting the number of interviews conducted to be from 20 to 50 participants (Larsson, 1993).

The analysis of the data gathered from the interviews constituted the basis of theory building in case studies (Eisenhardt, 1989). Data analysis is also seen as the most difficult (Eisenhardt, 1989) and most poorly developed (Yin, 2003) aspect of case study methodology. Yin (1994) adds that qualitative analysis relies to a great extent upon the investigator's own style of rigorous thinking. Data from the interviews were analyzed using NVivo (Version 1.3), a qualitative software package, which is the most widely used computer-based method of qualitative analysis (Ticehurst \& Veal, 1999). NVivo takes qualitative coding beyond coding and retrieval and integrates coding with qualitative linking, shaping, and modeling. A major objective was to build from the raw material towards a more general and conceptual set of findings, which is consistent with an inductive approach to qualitative data analysis (Miles \& Huberman, 1994). A conscious effort was made to understand the experiences of executioners in theoretical terms. A literature search was conducted using the themes 
that emerged in the data analysis phase. As a result, pertinent issues such as emotions at work, stress, coping mechanisms, dirty work, responsibility, and accountability at work appeared. The linking and comparing of the primary data with existing published research enabled the researcher to develop higher order categories and to assign conceptual labels as reference points. In order to increase the validity of the study and to ensure that the concepts were extracted from rather than imposed on the data, a research assistant reviewed the data analysis and interpretation phase.

\section{FINDINGS AND DISCUSSION}

The purpose of this case study was to verify and extend Clair and Dufresne's (2004) work and to explore how executioners experienced their responsibilities. The analysis of the data resulted in the emergence of four themes. Each theme alongside its particular findings will be drawn out, discussed, and related to the body of literature.

\section{Emotional responses and reactions}

The first main theme that emerged related to the emotional responses and reactions experienced by executioners. The data showed that the task responsibilities of the executioners were varied with regard to how close their duties brought them to the downsizing victims. Some executioners were responsible for purely administrative tasks pertaining to layoffs. Thus, their work responsibilities and physical location were less likely to bring them into direct contact with the victims and were less likely to experience emotional distress and trauma. An individual commented that "It was not people that I interacted with or even personally knew". In contrast, some executioners selected the victims, executed the actual layoffs, and even dealt with the victims after the layoffs. Thus, they were considerably more exposed to the emotional pain. Executioners were generally required to keep downsizing information confidential. This may include specific information about individuals who were to be laid off, procedures to be followed, and downsizing packages to be distributed. A number of executioners expressed that the need to keep information confidential and to deliberately lie to individuals to maintain secrecy conflicted with their personal values. This created dissonance (Weaver \& Agle, 2002). From a HR perspective, to be effective is to be genuinely concerned with the needs of individuals (Hansen, Kahnweiler, \& Wilensky, 1994). Again, some individuals expressed that they felt anxious and uncomfortable when pursuing their executioners' responsibilities. A 
senior individual commented "I cannot tell you how horrible I felt that I could not tell them that they were going to be fired until the downsizing was public".

Executioners expressed struggles concerning challenges of making decisions about the layoffs. Deciding who was to be laid off was seen by many as "very difficult", "tough", and related to "a lot of anxiety on my part". Executioners realized that all decisions needed to be justified and rationalized, yet there was a real sense of "subjectivity" since there were often "no clean victims among equally effective employees". There was also a strong sense of concern for people who were facing difficult times (e.g., health, marital, and financial issues). Executioners described processes as being "confusing", "chaotic", and "complex". They recognized that their decisions influenced their firms, their own areas, and, most importantly, individuals' lives in a most profound fashion. Moreover, executioners expressed frustrations when pressured to select the 'right' person given time and information constraints. An executioner expressed a concern about the lack of objectivity and information in the entire process. He stated that "Am I in a position to justifiably make the decisions that I am making about people's lives and careers?'.

Some executioners referred to their own roles as "toxic handlers" (Clair \& Dufresne, 2004). According to Frost (2003), toxic handlers are managers who shoulder the sadness, frustration, and anger of other individuals so that high-quality work can continue. They are the unsung corporate heroes to ease the pain of downsizing victims during major change programs (Frost, 2003). Executioners struggled with the responsibility for dealing with others' emotional trauma. Executioners mentioned toxic handlers' responsibilities, such as delivering the layoff news to individuals and dealing with employees' reactions following the layoffs. Some executioners stated that it was difficult to deliver bad news to people with whom they were well acquainted. This confirms Bandura, Barbarnelli, Caprara, \& Pastorelly's (1996) work. Some executioners referred to their attempts to empathize with the layoff victims that, according to them, led to considerable psychological fatigue and burnout. This aspect has been described as secondary traumatic stress (Grevin, 1996). This is particularly relevant given that executioners saw themselves as being responsible for causing others to experience anguish and pain.

\section{Coping mechanism - detached concern}

The second main theme that emerged was in relation to coping mechanisms. How do executioners deal with intense emotional situations surrounding the layoffs? How will they be able to deal with the emotional heat while focusing on their work 
and reducing their own personal distress at the same time? In most cases, executioners were aware of their own defensive behaviors. Holman (1990) discusses the notion of detached concern, which is a practice where physicians disconnect from the emotions of a situation to maintain objectivity and balanced decision making while simultaneously holding empathy for the patient (Clair \& Dufresne, 2004).

Applying the concept of detached concern and reflecting upon the case participants' responses, three key categories were identified: emotional, cognitive, and physical distancing. First, executioners detached and distanced themselves from the negative emotional turmoil that was occurring. Executioners employed a number of tactics, such as humor as well as the depersonalization of those being laid off. This enabled them to be prepared to make layoff decisions more rationally and objectively. Emotional distancing in relation to major change management traumas has been documented by Ashforth and Lee (1990) and Cordes and Dougherty (1993).

Second, executioners distanced themselves cognitively. The behavior of 'cognitive reframing though neutralizing techniques' (Bandura et al., 1996) involves an individual replacing the more negative aspects of a situation with more positive or at least neutral aspects. This allows the individual to avoid blame for actual or anticipated negative outcomes of a situation (Ashforth \& Lee, 1990) and to remain less emotionally involved in the process (Bandura et al., 1996).

Participants adopted a number of strategies, including normalizing, denial of injury, and perceptions of justice and fairness. Executioners engaging in normalizing (Clair \& Dufresne, 2004) saw layoffs as an inevitable reality of corporate life. This was demonstrated in executioners' comments, including "they [layoffs] are a fact of life" and "downsizing is part of corporate life". This helped executioners to appease ill feelings and personal responsibility for the layoffs. Denial of injury (Hong \& Duff, 1977) is a technique where executioners maintain that the layoff victims did not suffer harmful consequences. This was the case where individuals left unsatisfying jobs, were offered generous severance packages, or where the layoffs led to attractive job opportunities. An executioner stated "I felt comfortable with the package that they were offering" and "We felt good about being able to help the individuals get to their next assignment". A belief that the decisions were just and fair (Gilbert, 2000) helped appease feelings. A number of executioners commented that some situations were characterized by "mutual consent" where people were not performing in their roles or where they were not happy in their positions. Thus, the layoffs were "less disruptive" and "relatively painless". A few executioners stated that layoffs were seen as "opportunities" and viewed as "a new starting point" or "a new beginning". 
Third, executioners distanced themselves physically. This form of distancing, studied by Clark and LaBeff (1982) and Clair and Dufresne (2004), involves actions taken in order to avoid or leave situations where social difficulties and anxieties were anticipated. A number of executioners commented that they deliberately engaged in "avoidance tactics". This may have involved "staying out of sight", "hiding", and "minimizing visibility". According to the participants, these behaviors and actions enabled them to avoid "confrontations" and "compromising situations".

\section{Veteran executioners - the role of experience}

The third main theme that emerged was in relation to the importance of experience in conducting downsizing activities. A number of participants reported that there was a direct relationship between previous downsizing experience and personal emotional impact in that the downsizing experience produced effective coping mechanisms on the part of executioners. Some executioners referred to themselves as "veterans" and "seniors" and commented that carrying out layoffs has become "a routine" and "part of my job". The frequency and regularity of conducting downsizing activities leads to the development of 'coping mechanisms' (Clair \& Dufresne, 2004) and 'anticipatory coping' (Lazarus \& Folkman, 1984). The relationship between repetition of an event and emotional numbness on the part of individuals has been studied by Van Maanen and Kunda (1989) and Bandura (2002). There was also a strong sense of job focus whereby executioners carried out the "task" or "job" and not be "distracted" by the emotional impact of their actions. Again, there was an acknowledgment that previous experience enabled them to stay "on track" (Clair \& Dufresne, 2004).

\section{Relational proximity with victims}

The fourth main theme that emerged was in relation to relational proximity with victims. Accordingly, most executioners commented that it was more difficult to carry out layoffs if there were relational ties with the victims. Participants stated that having emotional connections and knowing about individuals' lives prevented them from being able to depersonalize their downsizing responsibilities (Clair \& Dufresne, 2004). Long-serving participants were more likely to be "involved" in people's lives. A participant commented "You know details about people's lives - their pregnant wives, their sick parents, their kids' problems”. Clearly, executioners that had deeper connections with employees and insights into colleagues' lives found that executing layoffs to be more taxing (Clair \& Dufresne, 2004). 


\section{PRELIMINARY CONCEPTUAL FRAMEWORK}

The findings in this case study demonstrate that executioners deal with considerable tension inherent to downsizing comparable to the pain and anxiety experienced by physicians and death-tellers. Executioners attempt to find a safe distance from which to carry out their downsizing work. Based on the findings, a preliminary conceptual framework depicting the executioners' reactions to carrying out downsizing has emerged. This is shown in Figure 1. First, the framework shows that the executioners are emotionally strained by downsizing activities (Finding 1) and they respond by distancing themselves emotionally, cognitively, and/or physically (Finding 2). These distancing reactions are coping mechanisms (Holman, 1990) in order to make the execution of individuals more bearable (Finding 1) while staying objective in the context of an emotionally charged situation (Finding 2). The framework shows that previous experience with downsizing activities may lead to emotional numbing which is likely to reduce the emotional stress experienced by executioners (Finding 3). In order to cope with the stress, executioners resorted to three strategies: normalizing, denial of injury, and the perception of justice and fairness (Finding 2). Strong relationships with downsizing victims also had an impact on executioners' emotional state (Finding 4).

Figure 1 Preliminary conceptual framework of executioners' reactions to layoffs

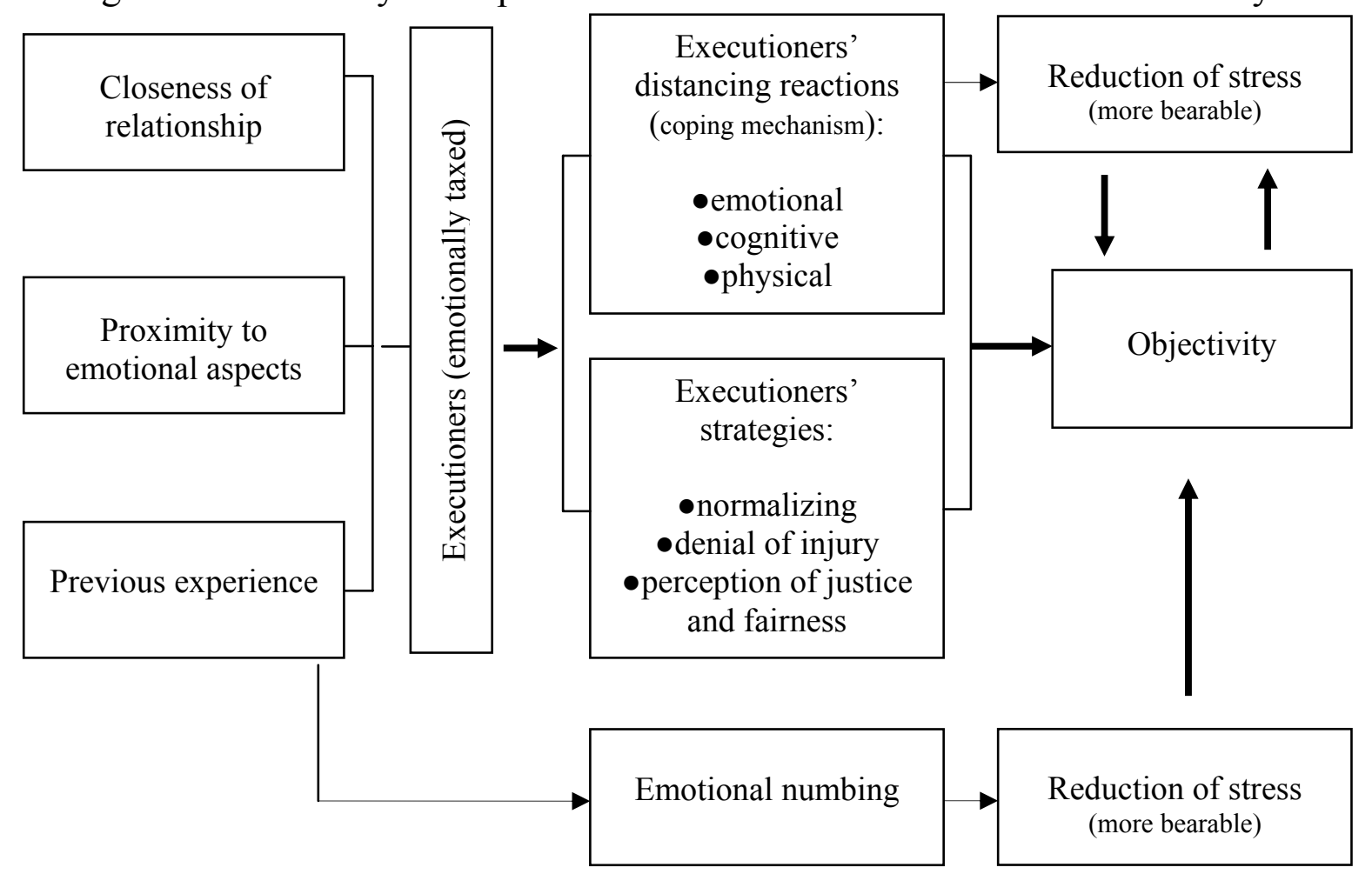

Source: based upon field data and adapted from Clair and Dufresne (2004) 


\section{CONCLUSION}

Strategic downsizing has been adopted by managers for more than two decades. A great deal of downsizing research has focused on the downsizing survivors and victims. This Australian case study explored how executioners experienced their downsizing responsibilities. The results of this study demonstrate that the work of executing downsizing activities is emotionally taxing and professionally challenging. It was shown that executioners distanced themselves from the tasks at hand emotionally, cognitively, and physically. These strategies were seen as coping mechanisms for self-protection and self-preservation on the part of executioners. It was revealed that previous downsizing experience had an impact on the work of executing downsizing activities enabling executioners to stay on task. Relational proximity as well as closeness and personal ties with individual victims also impacted the emotional state of executioners. This study generated a conceptual framework (Figure 1) depicting various aspects and facets of executioners' reactions to layoffs.

\section{IMPLICATIONS FOR PRACTICE AND THEORY}

The findings that have emerged have at least three implications for practice. First, it is imperative to recognize that the execution of downsizing has a profound impact upon survivors, victims, and the executioners. Executioners represent a second category of 'victims' in that they too suffer through the negative downsizing consequences. Thus, firms planning for a downsizing must provide executioners with the necessary training and emotional support. What should the required training entail? While more research in this area is needed, the training should at least raise awareness that executioners will experience a range of emotions. They will need to be equipped with tools and techniques that enable them to cope with the emotions associated with carrying out the tasks. Firms need to set up forums, social support groups, and employee assistance programs throughout the process (Clair \& Dufresne, 2004).

Second, this study has established that executioners detach themselves emotionally, cognitively, and physically. While executioners explore various means of self-protection and self-preservation, more research is required to ascertain whether coping behaviors on the part of executioners have adverse effects on the overall outcome of a downsizing. Third, the findings demonstrate that veteran executioners with prior downsizing experience were more likely to attain the state of 'emotional numbing' (see Figure 1). More research is required to determine whether it is more beneficial for firms to commission experienced executioners or to employ the services 
of external professional consultants and change agents.

The key findings have several implications for theory. For instance, the findings have implications for research on dirty work in firms. 'Dirty work' (Ashforth \& Kreiner, 1999) is work tainted by society and includes, among others, the work of garbage collectors and used-car salespersons. Ashforth and Kreiner's (1999) work examined how individuals in stigmatized occupations coped with the stigma, especially through a strong occupational subculture. This study has demonstrated that executioners' tasks were marked with social taint rendering them at least temporarily stigmatized (Clair \& Dufresne, 2004). It was further shown that there was no strong subculture among executioners. Thus, the coping mechanisms were more personal and individual, yet more fragile. Ashforth and Kreiner's (1999) work demonstrates that the ability to cope with performing a dirty role increases with repeated experience.

The key findings demonstrate that executioners show compassion and empathize with the victims. At the same time, they search for strategies to distance themselves from the layoff tasks and the victimized individuals. Trevino (1992) argues that the ability to take the perspective of and empathize with others is an attribute of effective leadership. Grevin (1996) warns that the cost of empathy is "compassion fatigue" (Clair \& Dufresne, 2004: p 16-19). The vast majority of executioners in this study felt the need to empathize, yet they were aware that they needed to distance themselves in order to preserve their well-being and emotional health. The research findings reveal that a greater understanding of the tension between compassionate and dispassionate aspects in theorizing about emotions in firms is indispensable (Clair \& Dufresne, 2004). This confirms the ever-increasing interest in the role and significance of emotions in organizations (Ashforth \& Humphrey, 1995). It has become clear that the loss of emotions or 'emotional numbing' is likely to be a direct result of continual, highly stressful major change (Kets de Vries, 1999). Thus, executioners are likely to remove themselves from toxic situations, including layoffs, and emotionally withdraw from situations they feel are harmful to others. If executioners employ empathy while executing layoffs they feel unjustified and intense negative emotions result. In order to combat such potentially negative emotions, executioners need to become more dispassionate players conducting downsizing activities with little or no concern for the victims. Future research will be needed to explore the tension between compassion and dispassion and whether the practice of detached concern is an effective strategy (Clair \& Dufresne, 2004). 


\section{LIMITATIONS}

The findings that have emerged from this study add to our understanding of an under-researched group - the executioners. At the same time, the research was exploratory and the findings have a number of limitations. First, the case study employed in this research constituted one of Australia's largest banks. The findings are confined to the case study and may not apply to the entire Australian banking industry. Second, the research was conducted concerning the latest downsizing round which constituted a large-scale downsizing involving significant depth and breadth (Cameron, 1994). The results may be different for small-scale and one-off events in which only a few individuals are directly affected. Third, the interviews were retrospective in nature. It is evident that longitudinal studies have the capacity to capture the experiences during all downsizing phases. Finally, the paper is principally based on and heavily relies on Clair and Dufresne's (2004) work. The study mainly sought to confirm and possibly extend Clair and Dufresne's (2004) original study.

\section{REFERENCES}

Adams, G.R., \& Schvaneveldt, J.D. (1991). Understanding Research Methods, $2^{\text {nd }}$ edition, New York: Longman Publishing Group.

Ashforth, B.E., \& Humphrey, R.H. (1995). Emotion in the workplace: A reappraisal. Human Relations, 48, 97-125.

Ashforth, B.E., \& Kreiner, G.E. (1999). How can you do it? Dirty work and the challenge of constructing a positive identity. Academy of Management Review, 24, 413-434.

Ashforth, B.E., \& Lee, R.T. (1990). Defensive behavior in organizations: A preliminary model. Human Relations, 43, 621-648.

Australian Bureau of Statistics (ABS) (1998). Employer Training Practices, Australia, Commonwealth of Australia.

Bandura, A., Barnbarnelli, C., Caprara, G.V., \& Pastorelli, C. (1996). Mechanisms of moral disengagement in the exercise and moral agency. Journal of Personality \& Social Psychology, 71, 364-374.

Bandura, A. (2002). Selective moral disengagement in the exercise of moral agency. Journal of Moral Education, 31, 101-119.

Berg, B.L. (1989). Qualitative Research Methods for the Social Sciences. Boston: Allyn and Bacon.

Bogdan, R.C., \& Biklen, S.K. (1998). Qualitative Research in Education, $3^{\text {rd }}$ edition. Boston: Allyn \& Bacon. 
Brockner, J. (1992). Managing the effects of lay-offs on survivors. California Management Review, 34, 9-28.

Burke, R.J. (1998). Downsizing and restructuring in organizations: Research findings and lessons learned - introduction. Revenue Canadienne des Sciences de l'Administration - Canadian Journal of Administrative Sciences, 15 (4), 297-299.

Cameron, K.S. (1994). Strategies for successful organizational downsizing. Human Resource Management, 33(2), 189-211.

Carson, D.J., Gilmore, A., Gronhaug, K. \& Perry, C. (2001). Qualitative Marketing Research, Thousand Oaks, CA: Sage Publications.

Clark, R.E., \& LaBeff, E.E. (1982). Death telling: Managing the delivery of bad news. Journal of Health and Social Behavior, 23, 366-380.

Clair, J.A., \& Dufresne, R.L. (2004). Playing the grim reaper: How employees experience carrying out a downsizing. Human Relations, 57(12), 1597-1625.

Cordes, C.I., \& Dougherty, T.W. (1993). A review and an integration of research on job burnout. Academy of Management Review, 18, 621-656.

Dewitt, R.L., Trevino, L.K., \& Mollica, K.A. (2003). Stuck in the middle: A controlbased model of managers' reactions to subordinates' lay offs. Journal of Managerial Issues, 15, 32-49.

Dolan, S., Belout, A., \& Balkin, D.B. (2000). Downsizing without downgrading: learning how firms manage their survivors. International Journal of Manpower, 21(1), 34-46.

Downs, A. (1995). Corporate Executions. New York, NY: Amacom.

Eisenhardt, K.M. (1989). Building theories from case study research. Academy of Management Review, 14(4), 532-550.

Finance Sector Union (2005). The Finance Sector: Workforce Report. Volume 1, FSU, Melbourne: Finance Sector Union of Australia.

Folger, R., \& Skarlicki, D.P. (1998). When tough times make tough bosses: Managerial distancing as a function of lay off blame. Academy of Management Journal, 41, 79-87.

Frost, P.J. (2003). Toxic emotions at work: How compassionate managers handle pain and conflict. Cambridge, MA: Harvard Business School Press.

Gandolfi, F. (2006). Corporate downsizing demystified: a scholarly analysis of a business phenomenon. Hyderabad, India: ICFAI University Press.

Gandolfi, F. (2007). An exploratory study of the process of downsizing of large Australian banks. Sasin Journal of Management, 13(1), 4-16. 
Gandolfi, F., \& Neck, P. (2003). Organizational downsizing revisited. The Australasian Journal of Business and Social Inquiry, 1(1), 16-29.

Gilbert, J.T. (2000). Sorrow and guilt: An ethical analysis of layoffs. S.A.M. Advanced Management Journal, 65(2), 4-13.

Grevin, F. (1996). Post-traumatic stress disorder, ego defense mechanisms, and empathy among urban paramedics. Psychological Reports, 79, 483-495.

Hansen, C.D., Kahnweiler, W.M., \& Wilensky, A.S. (1994). Human resource development as an occupational culture through organization stories. Human Resource Development Quarterly, 5, 253-268.

Holman, E.A. (1990). Death and the health professional: Organization and defense in health care. Death Studies, 14, 13-24.

Hong, I.K., \& Duff, R.W. (1977). Becoming a taxi-dancer: The significance of neutralization in a semi-deviant occupation. Sociology of Work and Occupations, 4, 327-342.

Keller, M. (1998) Downsizing in the New Zealand banking industry, Seminar paper presented to the Roche Consortium. University of Auckland, July 1998.

Kets de Vries, M.F.R. (1999). Organizational sleepwalkers: Emotional distress at midlife. Human Relations, 52, 1377-1400.

Kozlowski, S.J., Chao, G.T., Smith, F.M., \& Hedlund, J. (1993). Organizational downsizing: Strategies, interventions, and research implications, In C.L. Cooper \& I.T. Robertson (Eds), International review of industrial and organizational psychology. New York: Wiley.

Larsson, R. (1993). Case survey methodology: qualitative analysis of patterns across case studies. Academy of Management Journal, 36(6), 1515-1546.

Lazarus, R.S., \& Folkman, S. (1984) Stress, appraisals, and coping. New York: Springer.

Littler, C.R. (1998). Downsizing organizations: the dilemmas of change, Human Resources Management Bulletin. Sydney: CCH Australia Limited.

Macky, K. (2004). Organisational downsizing and redundancies: The New Zealand workers' experience. New Zealand Journal of Employment Relations, 29(1), 6387.

Miles, M.B., \& Huberman, A.M. (1994). Qualitative data analysis, $2^{\text {nd }}$ edition. Thousand Oaks, CA: Sage.

Mirabal, N., \& DeYoung, R. (2005). Downsizing as a strategic intervention. Journal of American Academy of Business, 6(1), 39-45. 
Morris, J.R., Cascio W.F., \& Young, C.E. (1999). Downsizing after all these years: Questions and answers about who did it, how many did it, and who benefited from it. Organizational Dynamics, 27(3), 78-87.

Noer, D. (1993). Healing the Wounds: Overcoming the Trauma of Layoffs and Revitalizing Downsized Organizations. San Francisco: CA Jossey-Bass.

Patton, M.Q. (1990). Qualitative Evaluation and Research Methods. Newbury Park, CA: Sage.

Perry, C. (1998). Processes of a case study methodology for postgraduate research in marketing. The New Zealand Journal of Business, 32, 9-10.

Silverman, D. (1997) .Qualitative Research. Sage Publications: Thousand Oaks, CA.

Ticehurst, G.W., \& Veal, A.J. (1999). Business Research Methods. Addison-Wesley Longman: Sydney.

Trevino, L.K. (1992). Moral reasoning and business ethics: Implications for research, education, and management. Journal of Business Ethics, 11, 445-459.

Van Maanen, J., \& Kunda, G. (1989). Real feelings: Emotional expression and organizational culture, In B. Staw \& L. Cummings (Eds), Research in organizational behavior. Greenwich, CT: JAI Press.

Weaver, G.R., \& Agle, B.R. (2002). Religiosity and ethical behavior in organizations: A symbolic interactionist perspective. Academy of Management Review, 27, 7797.

Wiesenfeld, B.M., Brockner, J., \& Thibault, V. (2000). Procedural fairness, managers' self-esteem, and managerial behaviors following a lay-off. Organizational Behavior and Human Decision Processes, 83, 1-32.

Williams, S.M. (2004). Downsizing - intellectual capital performance anorexia or enhancement? The Learning Organization, 11(4/5), 368-379.

Wright, B., \& Barling, J. (1998). The executioners' song: Listening to downsizers reflect on their experiences. Revue Canadienne des Sciences de l'Administration, $15,339-355$.

Yin, R.K. (1989). Case Study Research: Design and Methods. Sage Publications: Newbury Park, CA.

Yin, R.K. (1994). Case Study Research: Design and Methods, $2^{\text {nd }}$ edition. Sage Publications: Thousand Oaks, CA.

Yin, R.K. (2003). Case Study Research: Design and Methods, $3^{\text {rd }}$ edition. Sage Publications: Thousand Oaks, CA. 